\title{
Spontaneous Retinal Activity Is Tonic and Does Not Drive Tectal Activity during Activity-Dependent Refinement in Regeneration
}

\author{
Bradley J. Kolls and Ronald L. Meyer \\ Department of Developmental and Cell Biology, University of California, Irvine, California 92697
}

\begin{abstract}
During development, waves of activity periodically spread across retina to produce correlated activity that is thought to drive activity-dependent ordering in optic fibers. We asked whether similar waves of activity are produced in the retina of adult goldfish during activity-dependent refinement by regenerating optic fibers. Dual-electrode recordings of spontaneous activity were made at different distances across retina but revealed no evidence of retinal waves in normal retina or during regeneration. Retinal activity was tonic and lacked the episodic bursting associated with waves. Cross-correlation analysis showed that the correlated activity that was normally restricted to near neighbors (typically seen across 100-200 $\mu \mathrm{m}$ and absent at $>500 \mu \mathrm{m}$ ) was not altered during regeneration. The only change associated with regeneration was a twofold reduction in ganglion cell firing rates. Because spontaneous retinal activity is known to be sufficient to generate refinement during regen-
\end{abstract}

eration in goldfish, we examined its effect on tectal activity. In normal fish, acutely eliminating retinal activity with TTX rapidly reduced tectal unit activity by $>90 \%$. Surprisingly, during refinement at 4-6 weeks, eliminating retinal activity had no detectable effect on tectal activity. Similar results were obtained in recordings from torus longitudinalis. After refinement at 3 months, tectal activity was again highly dependent on ongoing retinal activity. We conclude that spontaneous retinal activity drives tectal cells in normal fish and after regeneration but not during activity-dependent refinement. The implications of these results for the role of presynaptic activity in refinement are considered.

Key words: goldfish; retinotectal system; tectum; spontaneous activity; regeneration; visual system; retinal activity; presynaptic activity
The visual system has been intensely studied as a model for the formation of ordered connections. One of the major findings to emerge is that impulse activity plays a critical role in generating order (Cline et al., 1996; Katz and Shatz, 1996; Shatz, 1996; Constantine-Paton and Cline, 1998). Although some of this activity is derived from visual stimulation, many of the organizational features of the visual system can be generated by spontaneous activity without visual experience, including anatomical retinotopic order in the retinotectal projection of lower vertebrates (Jacobson and Hirsch, 1973; Keating et al., 1986; Cook and Becker, 1990; Olson and Meyer, 1991), the laminar innervation and receptive field properties of dorsal lateral geniculate (dLGN) (Rakic, 1977; Sretavan and Shatz, 1984; Shatz, 1996; Cramer and Sur, 1997), eye-specific segregation in the dually innervated tectum of frogs and fish, and some properties of neurons in visual cortex (Cline et al., 1996; Katz and Shatz, 1996; Shatz, 1996; Constantine-Paton and Cline, 1998).

Locally correlated spontaneous activity in the retina has long been thought to drive activity-dependent ordering in the visual system by producing coactivity in the presynaptic and postsynaptic elements, which drives a Hebbian-like change in synaptic strength that stabilizes and strengthens the coactive synapses. Recordings from the retinas of adult cats, rabbits, and goldfish have shown that neighboring retinal ganglion cells (RGCs) exhibit correlated maintained activity in the dark (Arnett, 1975,

\footnotetext{
Received June 18, 2001; revised Dec. 26, 2001; accepted Jan. 23, 2002.

This work was supported by National Institutes of Health Grant EY6746 (R.L.M.) and the University of California Irvine Medical Scientist Training Program (B.J.K.).

Correspondence should be addressed to Ronald L. Meyer, Department of Developmental and Cell Biology, Biological Sciences II Building, University of California, Irvine, Irvine, CA 92697. E-mail: rlmeyer@uci.edu.

Copyright (C) 2002 Society for Neuroscience $0270-6474 / 02 / 222626-11 \$ 15.00 / 0$
}

1978; Arnett and Spraker, 1981; Maffei and Galli-Resta, 1990). In developing mammals, RGC activity has been found to be episodic, occurring in intermittent bursts that are propagated across the retina (Meister et al., 1991; Wong et al., 1993). Similar waves have been observed in the developing retina of turtles (Sernagor and Grzywacz, 1995). Pharmacological blockade of the waves with cholinergic antagonists disrupts the laminar innervation of the LGN in ferrets (Penn et al., 1998).

Although spontaneous correlated retinal activity, like that occurring in retinal waves, has been presumed to drive postsynaptic cells to produce refinement, direct evidence for this is limited. One study in mouse used an isolated retina-LGN preparation to show that the spontaneous retinal waves were associated with activity in LGN cells (Mooney et al., 1996). However, this in vitro preparation removed other inputs to geniculate neurons, such as from cortex, so it may not represent the true in vivo physiology. There is also a divergence of opinion about the function of retinal waves. In turtles, episodic activity has been linked to the formation of local retinal circuits rather than the patterning of optic afferents (Sernagor and Grzywacz, 1995, 1996; Burgi and Grzywacz, 1997); importantly, all of the evidence for retinal waves is from development, so their relevance to nerve injury and regeneration is completely unknown.

The present study investigates whether retinal waves occur during activity-dependent refinement of regenerating optic fibers in adult goldfish (Meyer, 1982, 1983; Schmidt and Edwards, 1983; Olson and Meyer, 1991) and whether spontaneous retinal activity drives tectal neurons. In normal goldfish, spontaneous retinal activity was tonic, devoid of wave-like activity, and exerted a major effect on tectal activity. During regeneration, however, no effect on tectal activity could be detected, and no retinal waves 
appeared. This suggests that spontaneous activity in regenerating optic fibers does not drive postsynaptic neurons during activitydependent refinement.

\section{MATERIALS AND METHODS}

Animals and optic nerve crush surgery. All animals were adult goldfish, Carassius auratus, between 5 and $15 \mathrm{~cm}$ in length. The fish were housed in standard glass aquariums at $20-22^{\circ} \mathrm{C}$ on a $12 \mathrm{hr}$ light/dark cycle. All surgical procedures were performed on fish anesthetized with tricaine methanesulfonate (Finquel, Sigma A-5040) using a dissecting scope and sterile instruments. The right optic nerve was crushed in the orbit $\sim 1 \mathrm{~mm}$ behind the eye by repeated compression with fine forceps. The fish were then returned to their tank, and regeneration was allowed to take place for 4-6 weeks, placing the animal in the window for refinement, or for 9-12 weeks, placing the animal in the post-refinement period.

In vivo preparation. This preparation has been described in detail elsewhere (Meyer, 1977, 1982; Lyckman and Meyer, 1995). Briefly, fish were anesthetized in Finquel and injected intramuscularly with curare at $2 \mu \mathrm{g} / \mathrm{g}$. To allow tectal recording, a window was cut in the skull overlying the tecta, and fatty tissue and pia were carefully dissected away. A steady flow $(0.5-1 \mathrm{ml} / \mathrm{min})$ of room temperature, balanced salt solution, $\mathrm{pH} 7.4$, containing (in mM): $120 \mathrm{NaCl}, 10 \mathrm{HEPES}, 1.5 \mathrm{KCl}, 1.5 \mathrm{CaCl}_{2}, 3.0$ $\mathrm{MgCl}_{2}$, and $0.5 \mathrm{Na}_{2} \mathrm{SO}_{4}$, was maintained over the tecta for the duration of the experiment. For retinal recording, a hole was made at the edge of the cornea using a sterile 26 gauge needle to provide a starting point for removal of the cornea. Fine dissecting scissors were used to cut around the cornea, which was then removed, allowing the lens to be carefully lifted out. For both retinal and tectal recordings, the fish was placed in a Plexiglas holder, and water was continuously passed over the gills via a recirculating pump. Recording began 15-20 min after the fish was placed in the holder, allowing the anesthesia to clear and the activity levels to stabilize. Stable recordings from both the retina and the tectum could be routinely made from this preparation for $>6 \mathrm{hr}$.

Intraocular TTX injections. In some fish, TTX was injected into the eye while recording from tectum. While the fish were anesthetized and being prepared for recording, a small hole was made in the dorsal surface of each eye on or near the limbus with a sterile 26 gauge needle. In contrast to the retinal recording preparation, the eye was otherwise left intact. The injection needle consisted of a Hamilton syringe equipped with glass pipette tip $\sim 10-20 \mu \mathrm{m}$ across. This injection needle was mounted in a micromanipulator so that TTX could be injected during recording with minimal mechanical disturbance. TTX was injected during the experiment after recording a 30-60 min pre-TTX period by inserting the injection needle through the hole in the eye and injecting $0.05 \mu \mathrm{l}$ of 1.2 mM TTX in $50 \mathrm{~mm}$ citrate buffer into the vitreous. Fish were tested for the presence of visual or light responses every 2 min after injection to ensure that action potential activity from the retina was blocked. Under these conditions, effects on tectal unit activity occurred $<10$ min after the injection, and complete blockade of visual and light responses occurred within $10-15 \mathrm{~min}$.

Tectal pharmacology. To nonspecifically block glutamate transmission in the tectum, solutions of $3 \mathrm{~mm}$ kynurenic acid (KA) with $0.2 \%$ DMSO were prepared in the above balanced salt solution with care to maintain the $\mathrm{pH}$ (7.4). Control solutions were the same balanced salt solution with $0.2 \%$ DMSO.

Stimulation. Bipolar stimulating electrodes were made from insulated stainless steel wires. Each wire had a tip diameter of $\sim 200-300 \mu \mathrm{m}$. Two wires were glued together with a separation of $<50 \mu \mathrm{m}$, producing electrodes that were $400-600 \mu \mathrm{m}$ across. These electrodes were placed on the optic nerve just behind the eye, and oil was placed in the orbit to reduce current spread and improve efficiency of stimulation. Supramaximal stimulation was achieved by passing 1-10 mA of current for 0.08$0.10 \mathrm{msec}$ using a photoisolation stimulator.

Immobilization via electrical lesion of spinal cord and cranial nerves. In a few animals, movement was prevented by lesioning the sensory and motor pathways without the use of any curare. Lesions were made by passing current through a bipolar, stainless steel electrode insulated to the tip. Current was applied for several seconds to the spinal cord and to the roots of cranial nerves III-V, V II, and IX. Care was taken to avoid the optic nerves, hypothalamus, and brainstem. These animals produced stable recordings for $3 \mathrm{hr}$ (the longest recording period), did not bleed profusely during or after lesioning, and had responses to visual and electrical stimulation comparable to curare-injected animals. Viability was followed during recording by looking at blood flow in vessels on the surface of the operculum just posterior to the eye.
Recording. Recordings were made using gold/platinum-plated tungsten electrodes. The tungsten electrodes were encased in glass with exposed, sharp, tapered tips, 2-30 $\mu \mathrm{m}$ in length. Electrodes were placed in the main optic layer of the tectum, in the torus longitudinalis nucleus, or in the RGC layer of the retina. As described in Results, these electrodes record cell bodies but not axons or axonal terminals. In the tectum and retina, electrode placement was verified by testing the visual responsiveness of the recorded units. Multiunit recordings were digitally recorded at $50 \mathrm{kHz}$ and stored using a DataWave acquisition system running on a PC. Data were collected continuously, but markers were placed in the data records every $10 \mathrm{~min}$ to allow division of the data into sequential $10 \mathrm{~min}$ blocks. These blocks were later used to define different portions of the experiment and to calculate average firing rates for groups of cells. All analysis was done off-line using DataWave software (see below).

Analysis. Average multiunit rates were computed in spikes per second and spikes per $100 \mathrm{msec}$. To calculate rates in spike per second, the data were processed in $10 \mathrm{~min}$ blocks to produce two to three block averages for each period before, during, and after TTX injection. All of the blocks before injection were combined to give an average control rate. The remaining blocks after TTX injection were normalized by dividing them by the average control rate producing a fraction of control values. The average rate in spikes per second, computed using 10 min blocks, represented a coarse following of changes in the average multiunit rate of activity after TTX injection. Rates were calculated in spikes per 100 msec for a small interval of the experiments. The $10 \mathrm{~min}$ before and the $30 \mathrm{~min}$ after TTX injection were isolated from each experiment, and the number of spikes in each $100 \mathrm{msec}$ interval of the data was counted. The rates based on the $100 \mathrm{msec}$ bins for each experiment within a given group (i.e., normal fish) were averaged and then plotted as a histogram. The multiunit records from the retina were also sorted into their individual units using the DataWave spike sorting analysis package as described previously (Lyckman and Meyer, 1995). Once the single units were isolated, their rates were calculated in spikes per second as described above for multiunit tectal rates.

Analysis of electrically evoked multiunit activity consisted of counting the number of spikes that occurred in each $2 \mathrm{msec}$ bin of the $10 \mathrm{msec}$ before and the $100 \mathrm{msec}$ after each stimulus. An average evoked unit response was generated from $10-40$ stimuli.

Cross-correlation analysis has been described in detail elsewhere (Perkel et al., 1967a,b; Kirkwood, 1979; Aertsen and Gerstein, 1985; Meyer and Brink, 1988; Lyckman and Meyer, 1995). Recordings were obtained in darkness. Briefly, cross-correlation analyses were performed on multiunit retinal recordings using the DataWave analysis package. To standardize the analysis, channel 1 was used as the "reference" channel, and the occurrence of units on channel 2, the "target" channel, was counted over various temporal ranges, before and after each reference event. We were interested in looking for waves of activity that would be expected to produce peaks between 1 and $10 \mathrm{sec}$ (Meister et al., 1991; Wong et al., 1993) as well as increased correlation over shorter distances that could produce peaks of $\leq 1 \mathrm{sec}$ (Arnett, 1978; Ginsburg et al., 1984). As a result, we chose to look at the occurrence of target events over three different temporal ranges: $50 \mathrm{msec}, 300 \mathrm{msec}$, and $1 \mathrm{~min}$ before and after each reference event. Theses temporal ranges were divided into smaller bins the height of which represents the number of target events that occurred for that time interval. Bin widths were $0.5,3$, and $30 \mathrm{msec}$ for the $\pm 50 \mathrm{msec}, \pm 300 \mathrm{msec}$, and $\pm 1 \mathrm{~min}$ ranges, respectively, generating 200 bins in the correlograms for the 50 and $300 \mathrm{msec}$ ranges and 4000 bins for the $1 \mathrm{~min}$ range. Correlograms were judged to be significant if there was a noticeable peak or valley near the center of the histogram as judged by visual inspection of the record. Although valleys represent negative correlations, they typically had flanking "hills" of positive correlation. For this reason, and because negative correlations could also be generated by retinal waves, valleys were counted along with peaks. In the case of the autocorrelations computed between multiple units recorded from one electrode, it was necessary to ignore the central bins associated with the contribution (depression) from the reference unit itself.

\section{RESULTS}

\section{Retinal waves are not detectable during refinement}

Single microelectrodes were used to record spontaneous ganglion cell activity in the retina in vivo to look for evidence of the episodic activity reported to occur during retinal waves. Recordings were obtained in normal fish, fish 4-6 weeks after optic nerve crush (refinement fish), and fish at 9-12 weeks after nerve 
crush (post-refinement fish). The 4-6 week period corresponds to the major period of activity-dependent refinement under our laboratory conditions (Meyer, 1982, 1983; Olson and Meyer, 1991). The normal numbers of synaptic connections have been reestablished by 4 weeks (Hayes and Meyer, 1988), but only a rough quadrant level retinotopic order can be discerned (Meyer, 1982, 1983; Olson and Meyer, 1991). Retinal activity is not required for the formation of this early projection. Retinotopic order dramatically improves by 6 weeks, and refinement is mostly completed by 8 weeks. This anatomical refinement takes place equally well in light or complete darkness (Cook and Becker, 1990; Olson and Meyer, 1991). However, during this period, refinement is completely and reversibly inhibited by eliminating spontaneous retinal activity with intraocular TTX (Meyer, 1982, 1983; Schmidt and Edwards, 1983; Olson and Meyer, 1991) or by synchronizing retinal activity with strobe illumination (Schmidt and Eisele, 1985; Cook and Rankin, 1986).

Recordings were of multiple units that were then decomposed into single units to produce ratemeter histograms. These histograms were then visually inspected for episodic activity. Example ratemeter histograms are shown in Figure 1. Activity was found to be continuous without evidence of periodic bursting in all three groups, including those in the refinement period. These recordings were initially done under ambient light conditions. Although retinal waves in development are not altered by illumination, it is conceivable that they might be suppressed in these adult retinas. To rule this out, recordings were also done in total darkness. The results were indistinguishable from those obtained with illumination (data not shown). These findings suggest that bursting activity is not present in normal retinas, nor is it induced in regenerating retinas after nerve crush injury.

Retinal waves in mammals appear to be generated by the cholinergic amacrine cells within the retina because they were inhibited by the nicotinic acetylcholine receptor antagonist D-tubocurare (Feller et al., 1996). It is conceivable that the curare that we were injecting intramuscularly to immobilize the fish was having effects centrally and inhibited similar waves from occurring during our recordings. Although an unlikely possibility because D-tubocurare does not cross the blood-brain barrier, we nevertheless sought to preclude this possibility by recording from retinas in animals that were immobilized by electrically lesioning the sensory and motor output tracts from the brain without the use of curare. The ganglion cells from these animals demonstrated the same continuous firing pattern as the animals injected with curare (Fig. 1C,D). Data from these animals were also included in the cross-correlation analyses discussed below, to control for any possible effects of curare. Thus, retinal bursting was not observed when interference from curare or any anesthetic was eliminated.

Although we did not see any evidence for bursting activity consistent with propagating waves across the retina, it might be argued that we missed them in simple inspection of activity records. Although such waves were readily identified with this method in previous reports (Meister et al., 1991; Wong et al., 1993), episodic activity might have been superimposed on a background of continuous activity in these adult retinas, making detection more difficult. To further pursue this, we used crosscorrelation analysis of recordings done under darkness as a more sensitive test of correlated firing (Kirkwood, 1979; Aertsen and Gerstein, 1985). Temporally associated activity between different units will generate peaks in cross-correlograms, even if only a small amount of the activity is temporally related. In retinas exhibiting wave activity, correlograms computed between recordings from neighboring electrodes display large, broad-based peaks on the order of 1-5 sec, with flat flanking regions containing low counts (Meister et al., 1991; Wong et al., 1993). The width of the peak is a summed effect of the duration of the burst episode and the propagation times of the wave between the recording positions. The low flat flanking regions outside the peaks indicate that there was little activity that was not correlated.

Similar cross-correlation analysis was performed on multiunit data recorded from two electrodes at various distances apart in the normal, refinement, and post-refinement goldfish. Autocorrelation analysis of multiunit records from individual electrodes was also performed because these effectively provide a record of different units that are immediate neighbors. Autocorrelograms from single electrodes and cross-correlograms computed between electrodes separated by $100-500 \mu \mathrm{m}$ typically produced peaks (Fig. 2) in the histograms, indicating that activity was often significantly correlated (Table 1) at these close distances, as reported previously (Arnett, 1978; Arnett and Spraker, 1981; Ginsburg et al., 1984). Some correlograms were flat, indicating the absence of correlated activity. These flat correlograms were observed more frequently in the cross-correlograms from the larger interelectrode distances (Table 1). Previous studies (Arnett, 1978; Arnett and Spraker, 1981; Ginsburg et al., 1984) also observed flat correlograms whenever the receptive field centers were nonoverlapping. Ganglion cells with overlapping receptive fields invariably showed significant correlations as long as the discharge rate was adequate for meaningful computation. There was no indication that the correlograms differed among normal, refinement, and post-refinement fish. In particular, there was no instance of correlograms with the large peak widths that had been observed with retinal waves. Peak (or valley) widths were typically $\sim 100 \mathrm{msec}$ wide, ranging from 80 to $200 \mathrm{msec}$, in all three groups and were closely comparable to those reported in previous studies on normal goldfish (Arnett, 1978; Arnett and Spraker, 1981; Ginsburg et al., 1984). It is also noteworthy that valleys (negative correlations) were seen in both normal and refinement fish. This contrasts with the correlograms produced by retinal waves, which are always peaked (positive). Cross-correlograms were also computed between units recorded at $\geq 500 \mu \mathrm{m}$. In all animals, including refinement fish, these invariably produced flat correlograms at all binning ranges (Fig. 2, Table 1), indicating an absence of detectable temporally correlated activity at these larger distances.

\section{Retinal activity is reduced during refinement}

During the preceding study, we noticed that the retinas from fish at 4-6 weeks after optic nerve crush appeared to have lower ongoing firing rates than either the normal or the post-refinement fish. To investigate this further, activity rates were measured in 23 multiunit recordings in six normal retinas, in 37 recordings from seven refinement retinas, and in 24 recordings from three postrefinement retinas. Comparison of these average multiunit rates demonstrated a dramatic reduction in retinas during refinement (Fig. 3, top). The average multiunit rates recorded from refinement retinas were two spikes per second compared with the six and seven spikes per second in both normal and post-refinement retinas (Fig. 3, top) $(p<0.02$; one-tail $t$ test). Recordings done under both continuous light and total darkness showed no significant differences in any of the groups (Fig. 3, bottom).

It has been shown that ganglion cells undergo morphological changes, such as somal swelling (Murray and Grafstein, 1969; 


\section{Retinal Ganglion Cells Fire Continuously}

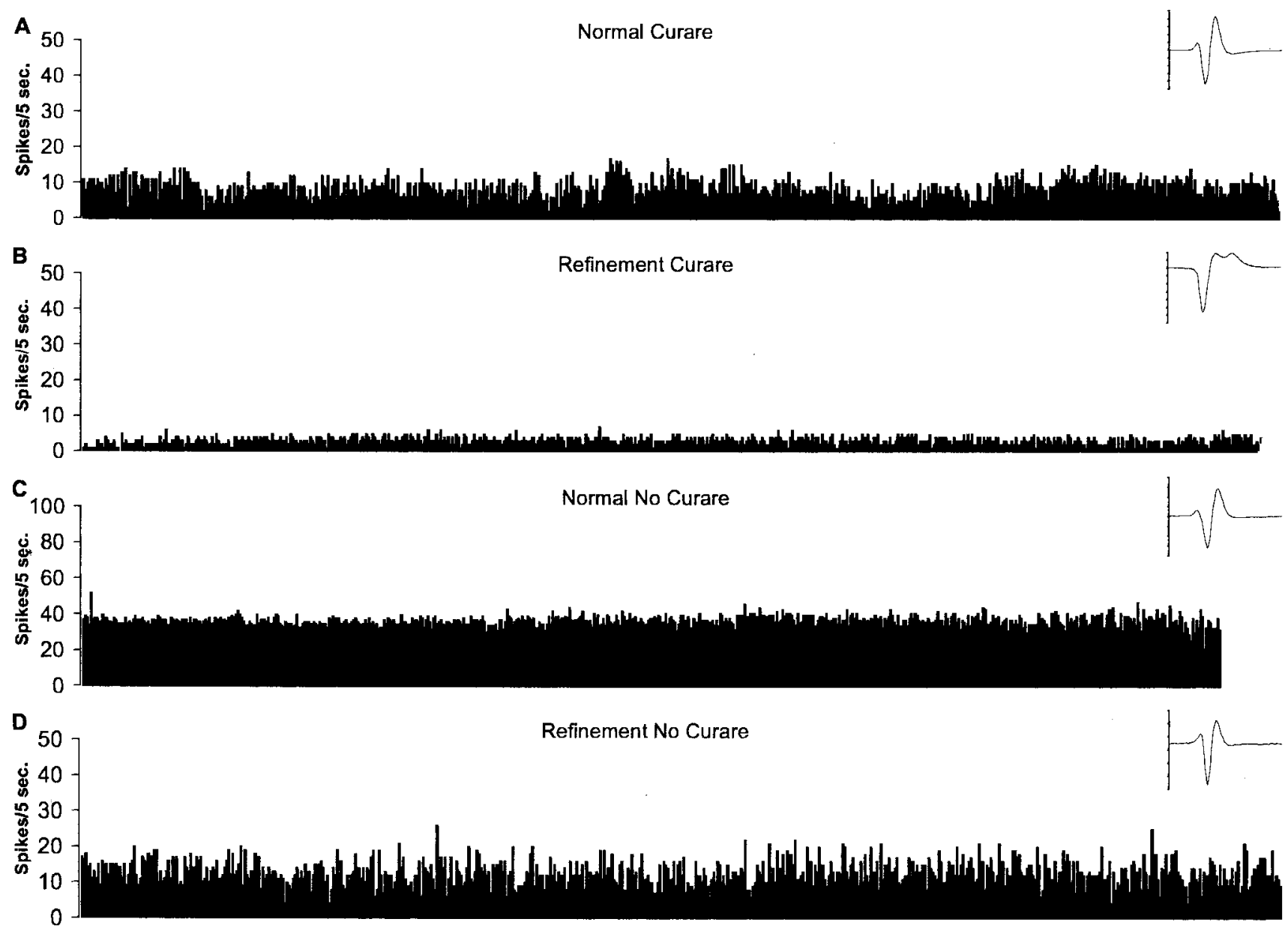

Figure 1. Example ratemeter histograms showing activity patterns of single retinal ganglion cells from normal and regenerating retinas. Top pair of records was recorded from normal $(A)$ and refinement $(B)$ retina (35 d after nerve crush). The fish were injected intramuscularly with D-tubocurare. Bottom pair of records (no curare) was from normal $(C)$ and refinement $(D)$ retina. These fish were not immobilized with curare; instead, the motor tracts were lesioned (see Materials and Methods) to immobilize them for recording. Insets show the average waveform for the single-unit event used to produce the histogram. Ratemeters are 10-min-long recording periods; ordinate is the number of events; inset units are arbitrary.

Murray and Forman, 1971), after nerve crush, and this could alter the number of cells sampled in the multiunit recordings. If fewer cells were recorded, this could produce artifactually low rates. To eliminate this possibility, we sorted our multiunit records into single units using multiparameter spike sorting (see Materials and Methods). Average single-unit spike rates were then computed for 73 normal, 75 refinement, and 60 post-refinement cells. As shown in Figure 4, the regenerating RGCs had rates that were less than half of normal cells.

\section{Spontaneous retinal activity drives tectal activity in normal but not regenerating fish}

It has been widely presumed that the spontaneous retinal activity drives postsynaptic activity during activity-dependent refinement. We tested this by acutely silencing ganglion cell activity in the retina while recording multiunit activity in the tectum during the refinement phase of regeneration. Recordings were first made from the tecta of normal fish to determine the dependence of ongoing tectal activity on spontaneous retinal activity. Stable multiunit recordings were obtained from the stratum fibrosum et griseum superficiale (SFGS) of tectum to obtain background levels of activity of ongoing tonic activity in the absence of visual stimulation, referred to as "spontaneous" tectal activity (Kolls and Meyer, 2000). TTX was then injected into the vitreous of the contralateral eye using a prepositioned injector while continuing to record. In an initial series of animals, onset of TTX blockage was determined by monitoring visually evoked activity. Evoked units showed partial decrement in 5-10 min and disappeared entirely within 10-20 min. Unevoked spontaneous tectal activity also began to decrease by $5-10 \mathrm{~min}$ and showed a major reduction after 10-20 $\mathrm{min}$. At $30 \mathrm{~min}$, activity rates in tectum were reduced by an average of $92 \%$ of that observed before TTX injection. The average suppressive effects of TTX on tectal unit rates in 13 normal fish are summarized in Figure 5 and Table 2. This effect was highly significant ( $\mathrm{p} \ll 0.00001$; paired $t$ test). Fish with control injections or fish recorded for comparable times showed no significant change in ongoing tectal activity rates.

These findings are consistent with spontaneous retinal activity exerting major excitatory drive on tectal cells in normal fish. An alternative interpretation, however, might be that we are primarily recording from the terminals of optic fibers instead of tectal 

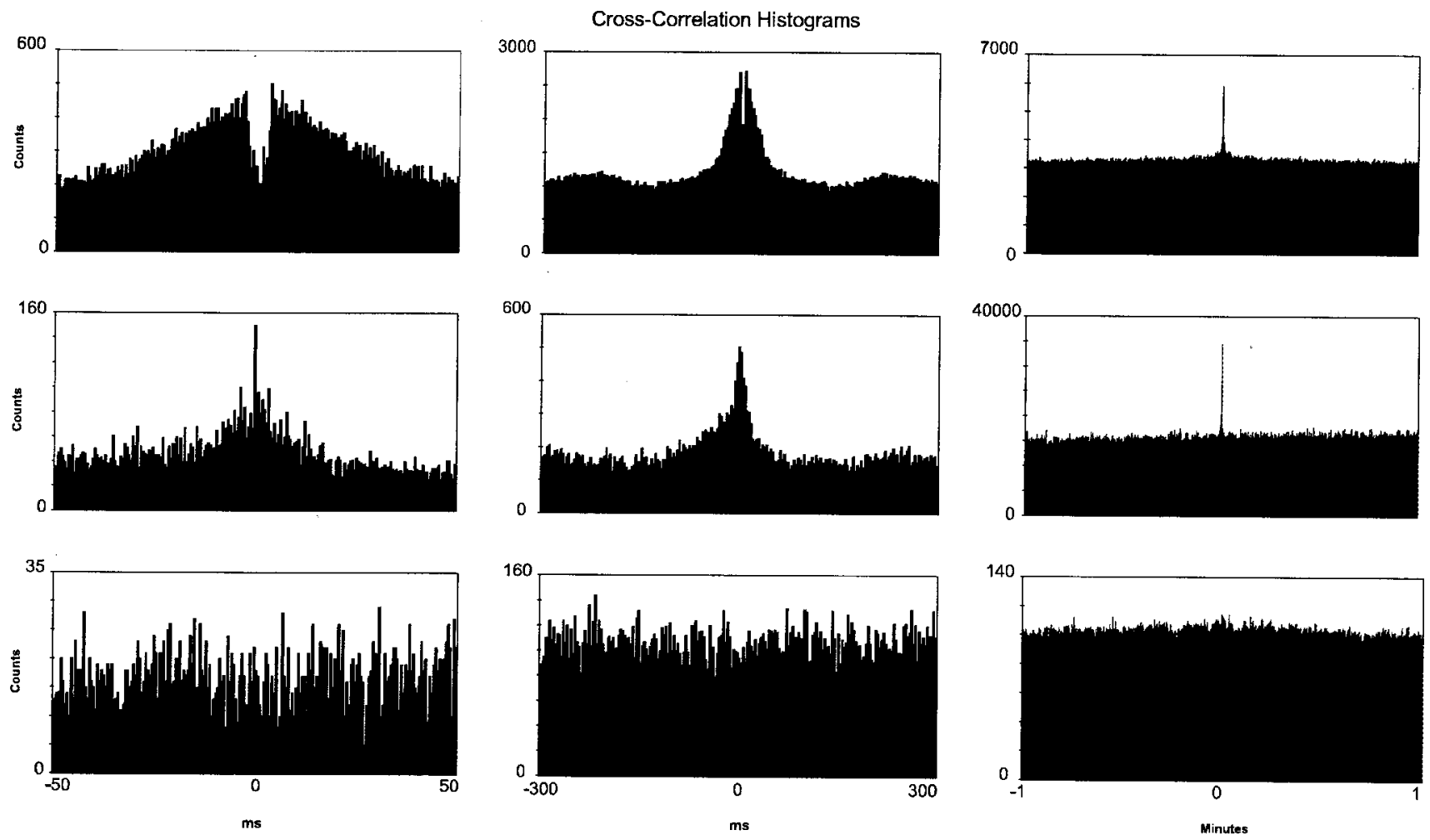

Figure 2. Example correlograms over various binning ranges at the same electrode or between near and distant electrode pairs. Top row is the autocorrelation of the multiunit record from a single electrode over short $( \pm 50 \mathrm{msec})$, intermediate $( \pm 300 \mathrm{msec})$, and long ( $\pm 1 \mathrm{~min})$ binning ranges. Peaks are present in each panel. The middle row is an example cross-correlogram between two electrodes, $200 \mu \mathrm{m}$ apart. A large central peak is present in each correlogram. Bottom row is an example cross-correlogram between two electrodes $>500 \mu \mathrm{m}$ apart, $800 \mu \mathrm{m}$ in this example. Peaks were not seen at any binning range. Bin widths were 1, 3, and $30 \mathrm{msec}$ for the $50 \mathrm{msec}, 300 \mathrm{msec}$, and $1 \mathrm{~min}$ ranges, respectively.

cells so that the large reduction in activity produced by the TTX simply reflects the silencing of optic fibers. Although it is clear that metal microelectrodes of the type used here do record from tectal cells within the SFGS of goldfish (O'Benar, 1976; Meyer and Brink, 1988; Lyckman and Meyer, 1995; Kolls and Meyer, 2000), the source of recordings in the tectum of frog and fish had historically been attributed to the terminal arbors of optic fibers (Lettvin et al., 1959). This was based on the known anatomy of the tectum and the receptive field properties of units. Subsequent anatomical studies (Potter, 1972; Hughes, 1990) and more detailed analysis of the receptive field properties in frog (Grant and Lettvin, 1991) have led to a revised view wherein units are thought to be solely postsynaptic. The current generated by optic terminals is apparently well below detectability with metal microelectrodes in frogs and mammals (Grant and Lettvin, 1991). A recent pharmacological study in reptiles has led to the same conclusion (Stirling et al., 1999).

Because a similar analysis has not yet been done for goldfish, we sought to determine the extent to which our recordings might be from optic terminals. Stable recordings of spontaneously active tectal units were obtained from the SFGS as above and then $3 \mathrm{~mm}$ KA was superfused over tectum to block optic transmission. After 40 min, activity was reduced by an average of $42 \%$ in 14 recordings as summarized in Figure 6. A subsequent injection of TTX into the eye eliminated all but a tiny fraction $(\leq 2 \%)$ of the remaining activity. This result indicates that at most $58 \%$ of our unit activity is presynaptic and at least $42 \%$ is postsynaptic in the normal goldfish. It is likely, however, that this is a significant overestimate of the contribution from optic fibers. We were unable to suppress the electrically evoked optic field potential by $>80 \%$, indicating that residual optic transmission remained. Consequently, some or all of the units recorded in kynurenic acid could be postsynaptic. Recent work using the same isolated retinotectal system used in the above mentioned study on reptile obtained complete suppression of the field potential and found that all units were postsynaptic (Stirling et al., 1999). Neverthe-

Table 1. Cross-correlation analysis of multiunit retinal recordings

\begin{tabular}{|c|c|c|c|c|}
\hline \multirow{5}{*}{$\begin{array}{l}\text { Normal } \\
\text { Refinement } \\
\text { Post-refinement }\end{array}$} & \multicolumn{4}{|c|}{ Multiunit Recordings \pm 1 minute Bin Range } \\
\hline & Auto & $100-200 \mathrm{~mm}$ & $300-500 \mathrm{~mm}$ & $>500 \mathrm{~mm}$ \\
\hline & $79 \% 46 / 58^{*}$ & $67 \% 6 / 9$ & $57 \% 4 / 7$ & $0 \% 0 / 12$ \\
\hline & $65 \% 30 / 46$ & $57 \% 47$ & $43 \% 3 / 7$ & $0 \% 0 / 9$ \\
\hline & $96 \% 44 / 46$ & $75 \% 6 / 8$ & $43 \% 3 / 7$ & $0 \% 0 / 8$ \\
\hline \multirow{5}{*}{$\begin{array}{l}\text { Normal } \\
\text { Refinement } \\
\text { Post-refinement }\end{array}$} & \multicolumn{4}{|c|}{ Multiunit Recordings $\pm 300 \mathrm{~ms}$ Bin Range } \\
\hline & Auto & $100-200 \mathrm{~mm}$ & $300-500 \mathrm{~mm}$ & $>500 \mathrm{~mm}$ \\
\hline & $88 \% 51 / 58$ & $67 \% 6 / 9$ & $12 \% 1 / 8$ & $0 \% 0 / 12$ \\
\hline & $56 \% 26 / 46$ & $57 \% 4 / 7$ & $29 \% 2 / 7$ & $0 \% 0 / 9$ \\
\hline & $89 \% 41 / 46$ & $75 \% 6 / 8$ & $14 \% 1 / 7$ & $0 \% 0 / 8$ \\
\hline \multirow{5}{*}{$\begin{array}{l}\text { Normal } \\
\text { Refinement } \\
\text { Post-refinement }\end{array}$} & \multicolumn{4}{|c|}{ Multiunit Recordings $\pm 50 \mathrm{~ms}$ Bin Range } \\
\hline & Auto & $100-200 \mathrm{~mm}$ & $300-500 \mathrm{~mm}$ & $>500 \mathrm{~mm}$ \\
\hline & $90 \% 52 / 58$ & $56 \% 5 / 9$ & $12 \% 1 / 8$ & $0 \% 0 / 12$ \\
\hline & $46 \% 21 / 46$ & $43 \% 3 \sqrt{7}$ & $14 \% 1 \pi$ & $0 \% 0 / 9$ \\
\hline & $54 \% 25 / 46$ & $50 \% 4 / 8$ & $0 \% 0 \pi$ & $0 \% 0 / 8$ \\
\hline
\end{tabular}

*Note: Data are summarized as the percentage of correlated histograms and the ratio of (peaked + troughed histograms)/(total number of cross-correlation histograms studied). 


\section{Average Multiunit Rates in Retina}
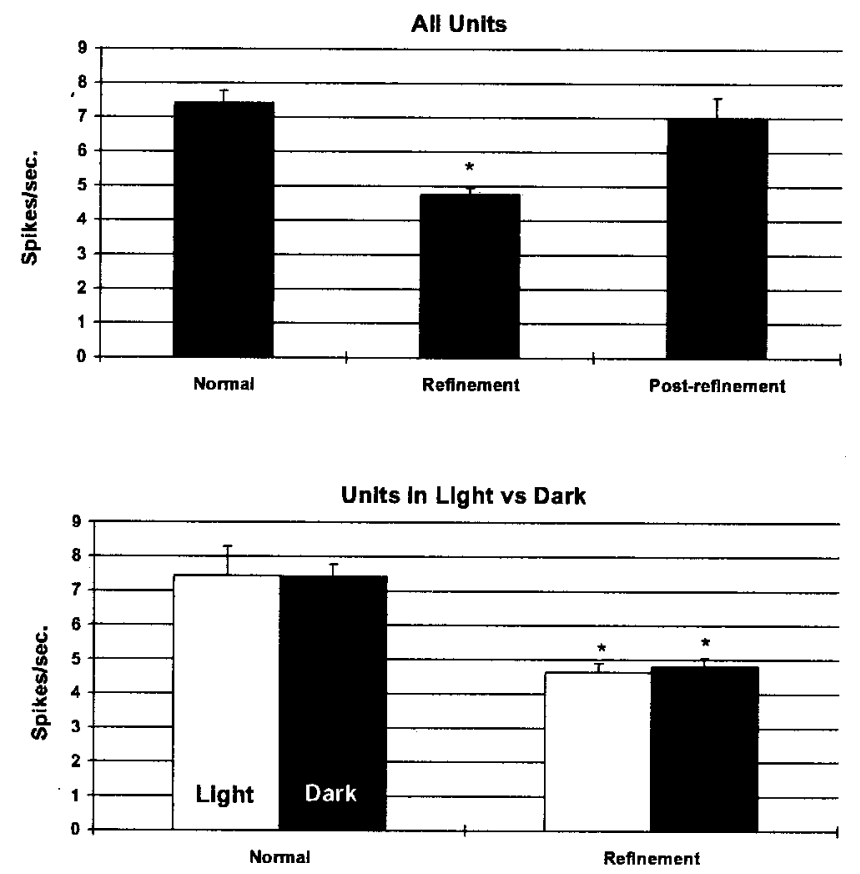

Figure 3. Bar chart summary of the average multiunit rates of normal and regenerating retinas. Top, The average multiunit rates for retinal ganglion cells from normal, $4-6$ week regenerating (Refinement), and $>15$ week regenerating (Post-refinement) retinas are plotted as the mean $\pm \mathrm{SE}$ for each group. The average multiunit rate in refinement tecta was significantly lower than the other two groups $\left({ }^{*} p<0.02\right.$; one-tail $t$ test). Bottom, The recordings were separated into those recorded with ambient lighting (white bars) and those recorded in total darkness (black bars) for normal and refinement tecta. No significant differences were found between the rates of activity in the light and dark. The multiunit rate was significantly lower in the refinement group both in the light and in the dark $\left({ }^{*} p<0.05\right.$; one-tail $t$ test).

less, to be conservative, we can correct the $92 \%$ suppression of tectal activity produced by intraocular TTX by an estimated contamination of optic fibers in the recordings of $58 \%$. In this case, tectal activity would be suppressed by $34 \%$. This is still a large and highly significant effect, indicating that spontaneous retinal activity does, in fact, strongly contribute to ongoing tectal activity.

To determine the extent to which spontaneous retinal activity contributes to tectal activity during activity-dependent refinement, acute intraocular TTX injections were performed at 4-6 weeks after optic nerve crush while ongoing tectal activity was monitored as above. Rather surprisingly, tectal activity showed no detectable decrease $30 \mathrm{~min}$ after TTX injection $(p>0.3$; paired $t$ test) (Fig. 5, Table 2.) One possible explanation for these results might be that during refinement tectal cells can readily compensate for the loss of optic drive by increasing their rate of firing. If this were so, one would expect to see a transient decrease followed by a compensatory increase. To determine whether this was occurring, we followed the rate of spontaneous unit activity with greater temporal resolution by calculating rates in $5 \mathrm{sec}$ intervals (bins) and looked for the predicted changes. In every case, ongoing activity remained unchanged, with no detectable transient decreases or compensatory increase as illustrated in Figure 7, further indicating that spontaneous retinal activity was

\section{Average Single Unit Rates in Retina}
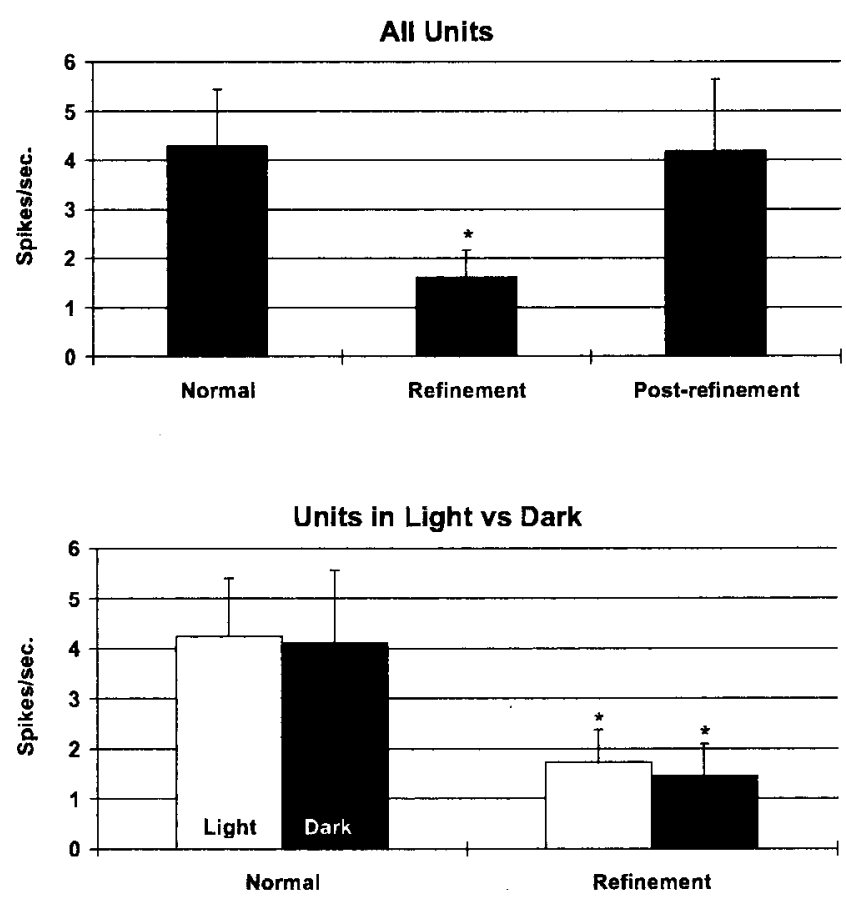

Figure 4. Bar chart summary of the average single-unit rates of normal and regenerating retinas. Animals and conventions are as in Figure 3. $T o p$, The average single-unit rate during refinement was significantly lower than the average rates in the other two groups $\left({ }^{*} p<0.02\right.$; one-tail $t$ test). Bottom, The recordings were separated into those recorded with ambient lighting (white bars) and those recorded in total darkness (black bars) for each group. No significant differences were found between the rates of activity in the light and dark. The single-unit rate was significantly lower in the refinement group both in the light and in the dark $\left({ }^{*} p<0.05\right.$; one-tail $t$ test).

not driving tectal activity. This result also implies that we were not recording from optic fibers during refinement.

This result was in striking contrast to that obtained in normal fish. In these, TTX produced a monotonic decrease in activity over a period of 10-20 min. Activity remained suppressed thereafter for the duration of the experiment (Fig. 7, top). It was also noteworthy that the process of injecting TTX produced some visual stimulation caused by hand movement near the eye. This produced a brief increase in activity at the time of injection, as seen by the transient rise in the rate histogram at the time of injection (Fig. 7, top). In fish during refinement, no change in rate was associated with the TTX injection (Fig. 7, middle). In fact, even without TTX, movement of small visual stimuli in the visual field rarely produced evoked activity in refinement fish, whereas the same stimuli almost always evoked unit activity in normal fish. This conforms with the earlier electrophysiological study by Schmidt and Edwards (1983) who reported that distinct tectal responses could not be driven by visual stimuli until after the period of activity-dependent refinement, although refinement occurred earlier under their laboratory conditions.

To determine whether this tectal independence from spontaneous retinal activity was specifically associated with refinement or simply the result of having crushed the nerve, this same experiment was repeated in fish at 100-110 d after nerve crush. Intraocular TTX reduced activity by an average of $70-80 \%$ 


\section{Effect of Intraocular TTX on Spontaneous Tectal Activity}
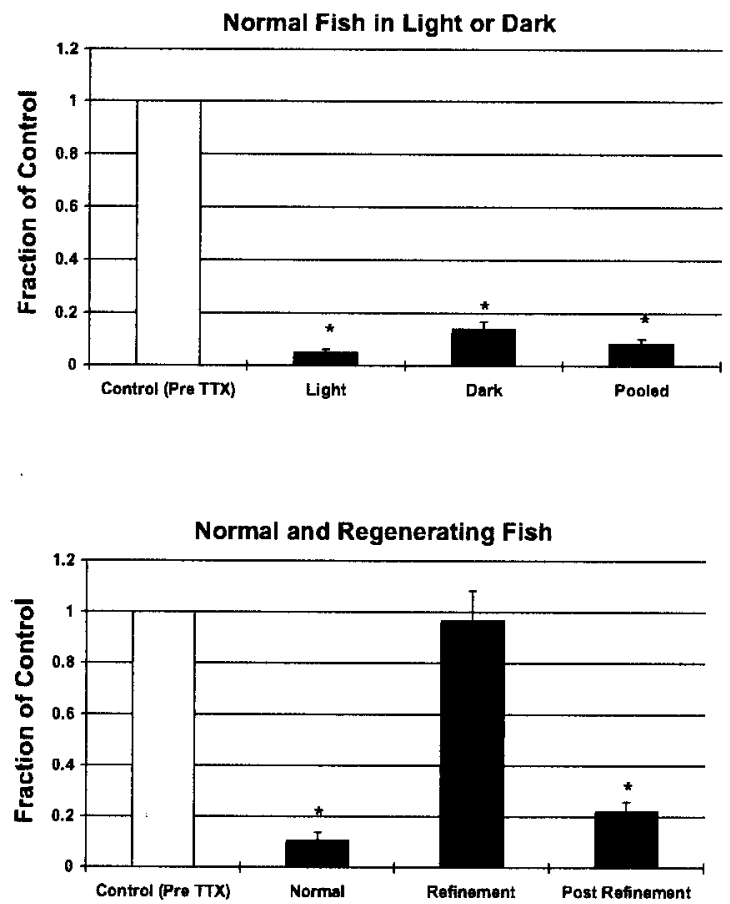

Figure 5. Histogram summary of the effects of acute intraocular TTX injection in normal, refinement, and post-refinement fish. Top, The average multiunit rate measured in normal tecta $30 \mathrm{~min}$ after intraocular injection of TTX was normalized to control and then plotted as the fraction of control level that remained $\pm \mathrm{SE}$ for recordings under ambient lighting (Light), total darkness (Dark), and the pooled average of these two groups (Pooled). The average level of activity in normal tecta was significantly reduced by $>90 \%$ independent of light levels $\left({ }^{*} p \ll 0.0001\right.$; paired $t$ test). Recordings made under ambient lighting were more suppressed than those recorded in total darkness ( $p<0.005$; one-tail $t$ test). Bottom, Multiunit rates were measured in normal, refinement, and postrefinement tecta $30 \mathrm{~min}$ after acute TTX injection. The measured rates were normalized to control levels that were averaged and plotted as the mean \pm SE fraction of control level activity. Normal (Pooled) data replotted from above and post-refinement were significantly suppressed $\left({ }^{*} p \ll 0.0001 ;\right.$ paired $t$ test $)$.

within 30 min after TTX (Fig. 5, Table 2) ( $p \ll 0.0001$; paired $t$ test). Examination of the change in rate in $5 \mathrm{sec}$ bins after administration of TTX demonstrated a rapid, long-lived depression similar to that seen in the normal tecta (Fig. 7, bottom). Visual stimuli also evoked activity, as seen by the transient increase in activity at the time of the TTX injection. Thus, after refinement, tectal activity again becomes highly dependent on spontaneous retinal activity.

One curious result was that intraocular TTX might have produced a modest increase in tectal activity in fish during activitydependent refinement. At $60 \mathrm{~min}$, the ratio of tectal activity relative to pre-TTX levels was above 1 , and this reached significance $(p<0.05)$. This would suggest that spontaneous optic activity was actually suppressing tectal activity. However, because this was not seen at $30 \mathrm{~min}$ when TTX appeared to be fully effective, and because this was not seen in all individual experiments (Fig. 7, middle), further work is needed before reaching definitive conclusions.
Table 2. Fraction of control activity after acute intraocular TTX injection

\begin{tabular}{|c|c|c|c|}
\hline \multirow{5}{*}{\begin{tabular}{|l} 
Light \\
Dark \\
Pooled
\end{tabular}} & \multicolumn{3}{|c|}{30 Minutes post intraocular $\Pi \mathrm{X}$ Injection } \\
\hline & Normal & Refinement & Post-Refinement \\
\hline & $0.048 \pm 0.014(8)^{*}$ & $0.905 \pm 0.157(11)$ & $0.167 \pm 0.025(4)$ \\
\hline & $0.138 \pm 0.030(5)$ & $1.341 \pm 0.168(7)$ & $0.384 \pm 0.091(4)$ \\
\hline & $0.083 \pm 0.019(13)$ & $1.066 \pm 0.116(18)$ & $0.276 \pm 0.060(8)$ \\
\hline \multirow{5}{*}{\begin{tabular}{|l} 
Light \\
Dark \\
Pooled
\end{tabular}} & \multicolumn{3}{|c|}{60 Minutes post intraocular $\pi \mathrm{X}$ Injection } \\
\hline & Normal & Refinement & Post-Refinement \\
\hline & $0.057 \pm 0.017(8)$ & $1.219 \pm 0.282(11)$ & $0.155 \pm 0.045(4)$ \\
\hline & $0.172 \pm 0.065(5)$ & $1.846 \pm 0.232(7)$ & $0.280 \pm 0.055(4)$ \\
\hline & $0.106 \pm 0.031(13)$ & $1.470 \pm 0.196(18)$ & $0.218 \pm 0.040(8)$ \\
\hline
\end{tabular}

*Note: Multiunit tectal recordings were standardized to pre-TTX levels that were averaged for all experiments. Averages are reported as mean \pm SEM (number of tecta).

\section{Intraocular TTX injection decreases activity in the torus longitudinalis}

As an additional measurement and to eliminate any possible sampling of optic fibers in the recordings, we similarly monitored the effect of retinal activity blockade on ongoing activity in the torus longitudinalis. The torus longitudinalis is an elongated nucleus that runs along the midline of each tectum. These neurons have both efferent and afferent connections with visually driven tectal cells but do not receive direct optic fiber innervation (Meek, 1983). If silencing the retina results in a drop in tectal cell activity, this will be reflected as a drop in toral cell activity. However, if silencing input does not alter tectal cell activity, then no change in toral rates should be seen. Stable multiunit recordings were obtained from torus, and TTX was injected into vitreous as above. In normal fish, tonic ongoing activity was obtained that dramatically decreased after TTX injection over a time course comparable to that seen for tectal activity. At 30 min after injection, TTX produced a significant $65-70 \%$ decrease in the average unit rates $(p<0.001$; paired $t$ test $)$ from seven experiments as shown in Figure 8, and the decrease persisted at $60 \mathrm{~min}$. In contrast, in fish during refinement, no significant change in rate

\section{Potential Contribution of Presynaptic Units to Tectal Recordings in Normal Fish}

Effect of Kynurenic Acid and Intraocular TTX on Spontancous Tectal Activity

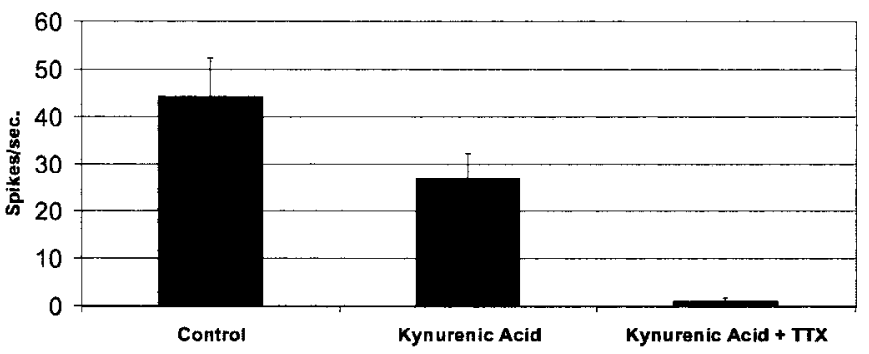

Figure 6. Analysis of presynaptic and postsynaptic contributions to the tectal multiunit recordings. In 14 recordings from normal animals, there was a consistent drop in unit activity after application of $3 \mathrm{~mm}$ kynurenic acid. The data represent the average level of activity over $20 \mathrm{~min}$ after 20-30 min of exposure to $3 \mathrm{mM} \mathrm{KA}$. Error bars indicate SEM. TTX was injected after $40 \mathrm{~min}$ of exposure to KA alone. In every case, there was a dramatic drop in the levels of unit activity to near zero or zero activity. 
Muitiunit Tectal Rates After Intraocular TTX
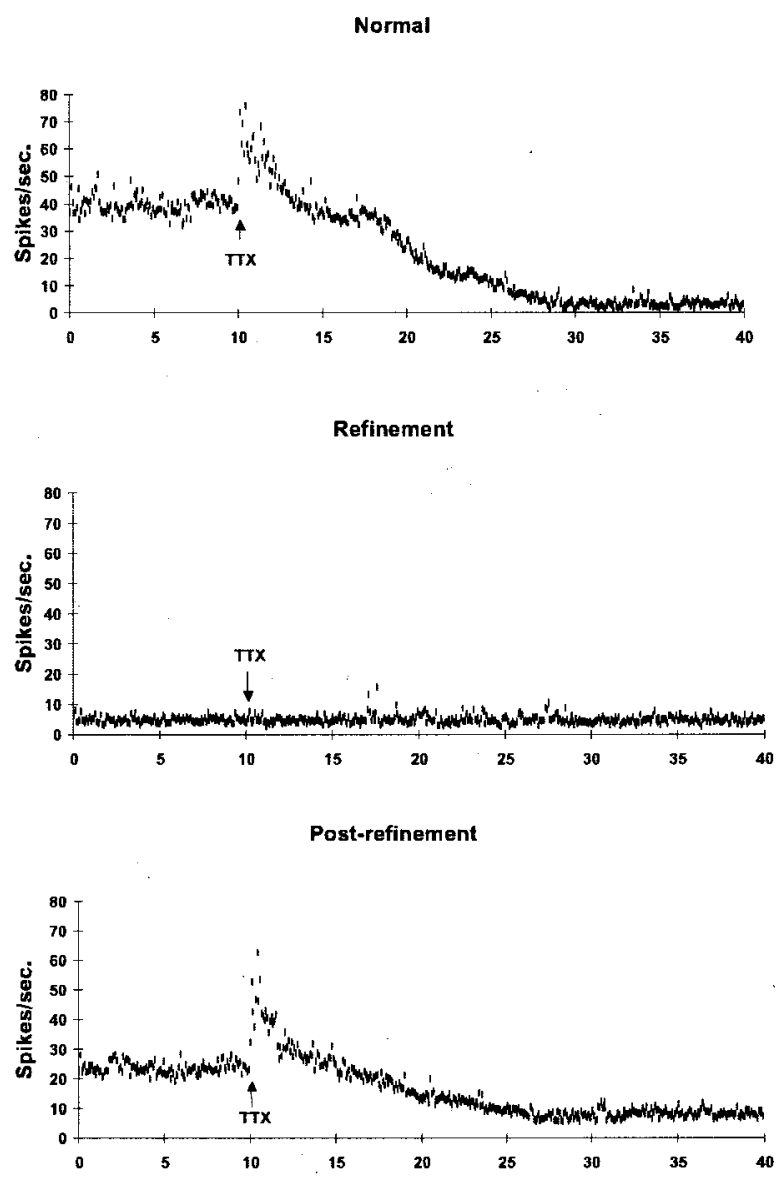

Figure 7. Changes in the average rate of multiunit tectal activity during intraocular TTX injection. Each plot is the average multiunit rate in $5 \mathrm{sec}$ bins for the $10 \mathrm{~min}$ before and $30 \mathrm{~min}$ after intraocular injection of TTX (arrow). Top (Normal), Average effects of acute TTX from nine normal fish. The large rise in rates immediately after TTX is the visual response to hand movement during injection. Rates decreased within $10 \mathrm{~min}$, and complete block of visual responses was attained within $20 \mathrm{~min}$. Middle (Refinement), Average affects of acute TTX from 19 fish during refinement. TTX injection had no effect on the ongoing multiunit rates of tectal activity. Bottom (Post-refinement), Average effects of TTX from nine post-refinement fish. TTX injection produced a visual response artifact similar to normal fish. Visual responses were blocked within 10-20 min, and clear reductions in rate were seen.

(Fig. 8) ( $p>0.05$; paired $t$ test; $n=8$ ) was observed at either 30 or $60 \mathrm{~min}$. This result further indicates that spontaneous retinal afferent activity does indeed drive tectal cells in normal fish but does not do so during refinement.

\section{Postsynaptic tectal cells are responsive to evoked optic input during refinement}

The preceding observations suggest that spontaneous optic activity is not driving tectal cells during regeneration. However, it might be argued that during refinement we were not able to record from tectal cells normally driven by optic fibers. This seems highly unlikely because we were recording from the main optic innervation layer, the SFGS, where optic fibers form $40 \%$ of all synapses and most of the cells are postsynaptic to optic fibers (Murray and Edwards, 1982; Hayes and Meyer, 1988). Nevertheless, we sought to confirm that we were recording from these cells by driving them through optic synapses. Although we were not

\section{Effect of Intraocular TTX on Unit Activity in the Torus Longitudinalis: Normal vs Refinement}

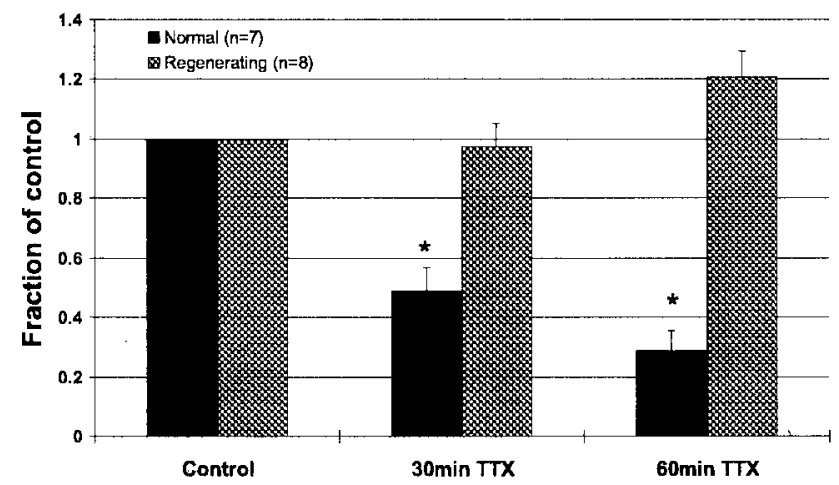

Figure 8. Differential effects of acute TTX on the rates of multiunit activity in the torus longitudinalis in normal and refinement fish. Multiunit rates were measured in the torus longitudinalis of normal (black bars) and refinement (gray bars) fish before and 30 and $60 \mathrm{~min}$ after intraocular TTX injection. The rates were normalized to control, averaged, and plotted as the mean fraction of control activity remaining \pm SE. Significant decreases in the multiunit rates were seen in normal fish, but no significant changes occurred in the rates of refinement fish $\left({ }^{*} p<0.002\right.$; paired $t$ test).

able to reliably evoke activity by moving visual stimuli (see above), we reasoned that this might be because of the lack of convergence during the refinement phase of regeneration or the unreliability of regenerating synapses. If so, it might be possible to evoke unit activity by synchronous activation of many optic fibers. To do so, we electrically stimulated the optic nerve and computed poststimulus histograms of activity using $2 \mathrm{msec}$ bins for a 100 msec duration that were averaged for several stimuli. The results from 9 recordings in 9 normal animals and 11 recordings from 10 refinement animals were then averaged and are summarized in Figure 9.

Electrical stimulation of the normal nerve evoked robust unit responses that showed an initial peak around $5 \mathrm{msec}$ followed by a second wave peaking at $\sim 20 \mathrm{msec}$. The early peak corresponded to the maximum negative component observed in the simultaneously recorded field potential. This negative wave has been attributed to a sink current generated by optic synapses within the SFGS. Stimulation of regenerating nerves during refinement also produced a robust unit response that was comparable in magnitude to that seen in normal fish. The evoked responses were more temporally dispersed. For example, many units were evoked in the $10-15 \mathrm{msec}$ bin in the regenerating animals compared with relatively few in normal fish. This is not surprising, because regenerating fibers are unmyelinated and follow circuitous routes to their target site. This would slow conduction and create temporal dispersion. These features were reflected in the field potential, which showed a longer and later negative wave. Many unit responses were evoked as late as $20-30 \mathrm{msec}$, which is too late to be presynaptic axons and therefore must represent tectal cells. These results indicate that the recordings were from tectal cells, which can be driven by optic fibers during refinement when synchronously stimulated.

\section{DISCUSSION}

The two major findings were that during the activity-dependent phase of regeneration, (1) retinal waves were not observed, and in 


\section{Electrical Stimulation of Optic Nerve Drives Tectal Units}

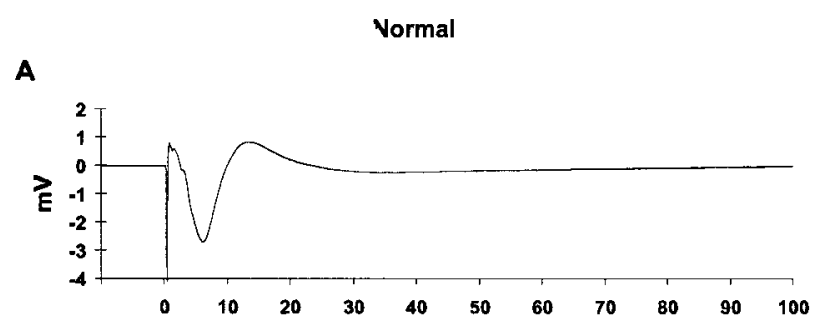

$\mathbf{B}$

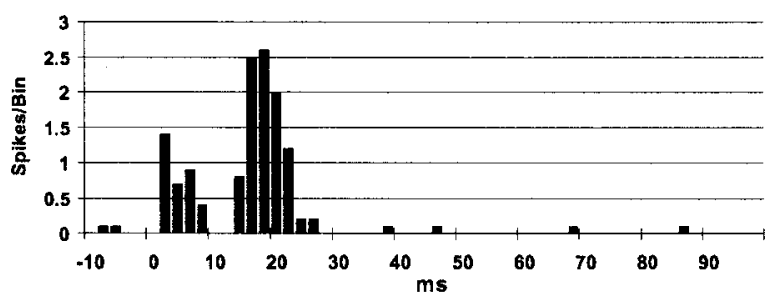

C

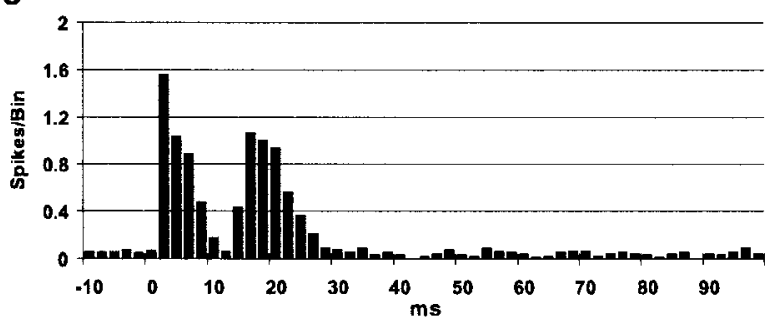

D

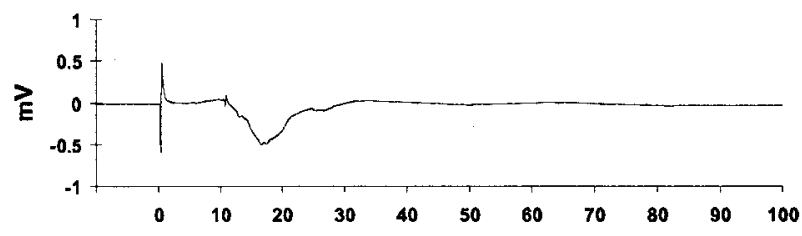

$\mathbf{E}$

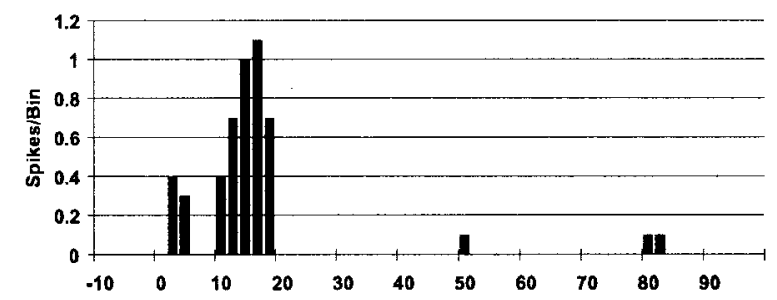

F

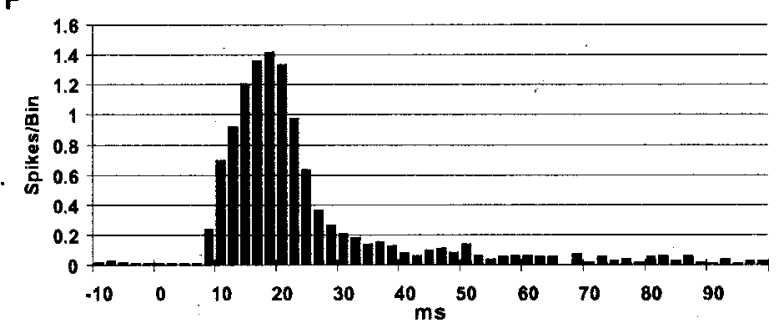

Figure 9. Electrically evoked responses in normal and refinement tecta. $A-C$, Electrical stimulation of the optic nerve in a normal fish produces field potential $(A)$ and unit $(B)$ responses. The field response and the unit histogram are the average results of 20 stimuli in one fish. The average unit response to 20-30 stimuli was calculated for each of nine fish, and then these average responses were combined to generate the overall average for all nine fish shown in $C$. $D-F$, Same as $A-C$ except that eight refinement fish were used. Evoked field and unit responses were consistently present at this time in these regenerating animals. $D, E$, Average results from 20 stimuli in one fish. $F$, Overall average for all eight refinement animals. Bin heights in the histograms are the average number of units evoked in the given $2 \mathrm{msec}$ bin.

fact, activity was suppressed, and (2) spontaneous retinal activity had no detectable effect on tectal activity.

\section{Retinal waves are not detectable in normal retina or during regeneration}

We looked for retinal waves by inspecting the pattern of activity in raw data records and ratemeter histograms in single and multiunit recordings from ganglion cells in situ in the absence of visual stimulation. In normal retina, ganglion cells showed tonic ongoing activity similar to that seen previously in vitro in adult mammals (Arnett and Spraker, 1981; Maffei and Galli-Resta, 1990) and fish (Arnett, 1978; Ginsburg et al., 1984). At 4-6 weeks after optic nerve crush, the pattern of ongoing activity was similarly continuous, the only difference being a two- to threefold reduction in rate as seen previously (Northmore, 1987; Oh and Northmore, 1998). In particular, there was not a single instance of the type of phasic activity associated with retinal waves during development in which ganglion cells burst for $1-5 \mathrm{sec}$ and then are silent for 30-100 sec (Meister et al., 1991; Wong et al., 1993; Sernagor and Grzywacz, 1995, 1996).

We also looked for evidence of waves with cross-correlation, which is a very sensitive tool for detecting temporal relationships between units (Aertsen and Gerstein, 1985). Retinal waves have been reported to be generated at a frequency of approximately one wave every 30-100 sec from variable positions and propa- gated at 80-140 $\mu \mathrm{m} / \mathrm{sec}$ (Meister et al., 1991; Wong et al., 1993). Between waves, RGCs were essentially silent. This kind of activity would invariably produce cross-correlograms between neighboring RGCs that have large central peaks with flanking regions near zero. A valley (negative correlation) would not be expected and has never been reported. For RGCs that are very close, the width of the peak would be primarily determined by the burst duration. With increasing distance between RGCs, the peak broadens from the relatively slow propagation rate and decreases in height, reflecting decreased temporal correlation. This distance-dependent broadening would be further increased by the origination of waves at different locations and propagation along diverse vectors that would produce differing phase shifts (Meister et al., 1991; Wong et al., 1993).

Correlograms computed between units at different retinal distances revealed comparable degrees of correlation in normal and regenerating retinas (Table 1). An increase in correlation expected from waves during regeneration was not detected. The characteristics of the correlograms were also inconsistent with the existence of retinal waves. Approximately one-half of the correlograms in both normal and regenerating retina exhibited valleys (negative correlations). Retinal waves should only generate peaks (positive correlations). The peak width was narrow, characteristically $100 \mathrm{msec}$, in contrast to the peaks several seconds wide 
induced by waves. The width was unaffected by interelectrode distance, consistent with common (vertical) input. Laterally propagating waves produce progressively broader peaks with increasing electrode separation. Only $25 \%$ of the correlograms computed for interelectrode separations of 300-500 $\mu \mathrm{m}$ were correlated, and none were correlated for larger distances. Retinal waves would be expected to produce correlations beyond $500 \mu \mathrm{m}$. Because the correlograms were computed for a large range of bin width and temporal windows, these results not only rule out the type of retinal waves seen during development but also render waves with other spatiotemporal characteristics (e.g., higher propagation velocity, shorter bursts) highly unlikely.

\section{Spontaneous retinal activity normally drives tectal activity but not during activity-dependent refinement}

In normal fish, spontaneous activity in retinal ganglion cells was found to make a major contribution to the spontaneous activity in neurons in the primary optic innervation lamina of tectum. We estimate that retinal activity contributes to $40-92 \%$ of ongoing tectal activity on the basis of the acute reduction in tectal activity after retinal activity blockade. For technical reasons (see Results), it is quite likely that the higher estimate is correct. This is also suggested by the recordings from toral neurons, which are postsynaptic to tectal neurons and showed a $70 \%$ reduction in ongoing activity after retinal blockade. This finding is not surprising, perhaps, considering that optic fibers make $40 \%$ of the synaptic connections in this lamina, show high spatial convergence, and exhibit locally correlated spontaneous activity.

In contrast, in fish at 4-6 weeks of regeneration, spontaneous retinal activity exerts no detectable effect on tectal activity. Acute retinal blockade had no chronic or transient effect on activity in tectal or toral neurons. There was substantial ongoing postsynaptic activity, but it was simply unchanged by eliminating ongoing retinal activity. Electrical stimulation of optic fibers did produce robust activity in tectal cells that was comparable to that of normal fish. Thus, tectal cells can respond to strong synchronous activity in optic fibers but apparently not to ongoing spontaneous retinal activity.

There are two likely reasons for this. One is that spontaneous retinal activity is substantially reduced (two- to threefold) during this period of regeneration. This finding of a two- to threefold reduction in ongoing activity during regeneration is in good agreement with two similar previous studies on goldfish (Northmore, 1987; Oh and Northmore, 1998). Using multiunit recordings from the optic nerve (Northmore, 1987) and single-unit recordings from the retina (Oh and Northmore, 1998), Northmore and colleagues found that activity in the retinal ganglion cells decreases after transection of the optic tract and subsequently returns to normal in late regeneration. Our results essentially confirm their earlier findings and extend them to optic nerve crush injury and to the recording conditions used in the present study.

One possible explanation for the reduction in rate, which was argued by Northmore (1987), is that morphological changes in the RGCs in response to the nerve crush result in changes in excitability of the cells. Changes in morphology such as increased size and nuclear changes (Murray and Grafstein, 1969; Murray and Forman, 1971) and reductions in the size of dendritic arbors occur after axotomy (Murray and Forman, 1971; Purves, 1975). In several brain regions in different animals, a loss of synaptic contacts on the dendrites follows axotomy, a phenomenon referred to as synaptic stripping (Purves, 1975; Cotman et al., 1981;
Graeber et al., 1993). This loss of synaptic input is associated with reduced activity.

The other explanation for why tectal cells are apparently not being driven by spontaneous retinal activity during regeneration is that regenerating fish may lack the necessary convergence to effectively drive tectal cells. Although the normal numbers of synapses are reformed by $30 \mathrm{~d}$, retinotopography is quite poor. Optic fibers from neighboring ganglion cells are dispersed over an area of tectum several times larger than normal (Adamson et al., 1984; Olson and Meyer, 1991). This may also explain why tectal units were difficult to drive with small visual stimuli. With time, regenerating fibers reform fine retinotopy, and spontaneous retinal activity returns to normal levels. Spontaneous retinal activity was again found to exert a strong effect on ongoing tectal activity closely comparable to normal fish.

\section{Implications for the model of activity-dependent refinement}

The finding that silencing the retina has no effect on ongoing tectal activity at 4-6 weeks of regeneration was rather surprising, because this corresponds to the main period of activitydependent refinement in the goldfish (Meyer, 1982, 1983; Olson and Meyer, 1991). Although this retinotopic refinement requires activity, it does not require visual stimulation because it occurs in the dark and in the absence of patterned visual input (Cook and Becker, 1990; Olson and Meyer, 1991). This is also true for the activity-mediated development of retinotopy in frogs, the formation of ocular dominance columns in fish and frog, and the segregation of fibers into eye-specific lamina in mammalian geniculate (Keating et al., 1986; Katz and Shatz, 1996; Cramer and Sur, 1997). Because eliminating spontaneous retinal activity (Meyer, 1983; Schmidt and Edwards, 1983) and synchronizing activity (Schmidt and Eisele, 1985; Cook and Rankin, 1986) both prevent retinotopic refinement, it has been widely presumed that these activity-mediated processes are normally driven by the locally correlated spontaneous activity in retina, the rule being that fibers that fire together, terminate together (Meyer, 1982). The mechanism has been widely hypothesized to be a synaptic rearrangement based on Hebbian-like strengthening of coactive synapses via the NMDA receptor (Katz and Shatz, 1996; Constantine-Paton and Cline, 1998). Coactive synapses drive the postsynaptic cell to fire, open the NMDA channels, and somehow become stabilized.

In contrast, the present finding implies that spontaneous retinal activity does not drive tectal activity during retinotopic refinement in goldfish. Although this may be true for retinal waves in the mammalian retinogeniculate system, it apparently is not true for regeneration in goldfish where retinal waves are absent, spontaneous activity is reduced, and spontaneous retinal activity is ineffective at generating tectal activity. In goldfish, spontaneous impulse activity in optic fibers apparently does not produce de novo correlated impulse activity in tectal cells.

How spontaneous retinal activity can generate activitydependent refinement without driving the postsynaptic cells will require further investigation. One possibility is suggested by the recent observation that neighboring tectal cells exhibit high levels of locally correlated bursting during regeneration (Kolls and Meyer, 2000). Although this bursting activity does not require activity in optic fibers, it is conceivable that the timing of the bursts could be regulated by optic activity. If optic fibers could synchronize the tectal burst with their own discharge, then this might lead to activity-dependent refinement through a traditional 
Hebbian-like mechanism. An alternative possibility is that spontaneous retinal activity caused sufficient depolarization of tectal cells to stabilize synapses without producing impulse activity in the tectal cell. This would be consistent with the finding from three-eyed frogs (Katz and Constantine-Paton, 1988) and ciliary ganglia (Purves and Hume, 1981) that synapses sort onto individual dendrites. This suggests that major dendrites, rather than the entire cell, may be the correlation detector. In any case, because spontaneous retinal activity comes to drive tectal activity after activity-dependent refinement is completed but not during refinement itself, this suggests that driving postsynaptic activity with spontaneous presynaptic impulses may be an end product of refinement rather than the cause of refinement.

\section{REFERENCES}

Adamson J, Burke J, Grobstein P (1984) Recovery of the ipsilateral oculotectal projection following nerve crush in the frog: evidence that retinal afferents make synapses at abnormal tectal locations. J Neurosci $4: 2635-2649$.

Aertsen AM, Gerstein GL (1985) Evaluation of neuronal connectivity: sensitivity of cross-correlation. Brain Res 340:341-354.

Arnett D, Spraker TE (1981) Cross-correlation analysis of the maintained discharge of rabbit retinal ganglion cells. J Physiol (Lond) 317:29-47.

Arnett DW (1975) Correlation analysis of units recorded in the cat dorsal lateral geniculate nucleus. Exp Brain Res 24:111-130.

Arnett DW (1978) Statistical dependence between neighboring retinal ganglion cells in goldfish. Exp Brain Res 32:49-53.

Burgi PY, Grzywacz NM (1997) Possible roles of spontaneous waves and dendritic growth for retinal receptive field development. Neural Comput 9:533-553.

Cline HT, Wu GY, Malinow R (1996) In vivo development of neuronal structure and function. Cold Spring Harbor Symp Quant Biol 61:95-104.

Constantine-Paton M, Cline HT (1998) LTP and activity-dependent synaptogenesis: the more alike they are, the more different they become. Curr Opin Neurobiol 8:139-148.

Cook J, Becker D (1990) Darkness and diurnal light are equally effective for activity-dependent refinement of the regenerating retinotectal projection in goldfish. Eur J Neurosci 2:162-169.

Cook JE, Rankin EC (1986) Impaired refinement of the regenerated retinotectal projection of the goldfish in stroboscopic light: a quantitative WGA-HRP study. Exp Brain Res 63:421-430.

Cotman CW, Nieto-Sampedro M, Harris EW (1981) Synapse replacement in the nervous system of adult vertebrates. Physiol Rev 61:684-784.

Cramer K, Sur M (1997) Blockade of afferent impulse activity disrupts on/off sublamination in the ferret lateral geniculate nucleus. Dev Brain Res 98:287-290.

Feller MB, Wellis DP, Stellwagen D, Werblin FS, Shatz CJ (1996) Requirement for cholinergic synaptic transmission in the propagation of spontaneous retinal waves. Science 272:1182-1187.

Ginsburg KS, Johnsen JA, Levine MW (1984) Common noise in the firing of neighbouring ganglion cells in goldfish retina. J Physiol (Lond) 351:433-450.

Graeber MB, Bise K, Mehraein P (1993) Synaptic stripping in the human facial nucleus. Acta Neuropathol 86:179-181.

Grant A, Lettvin J (1991) Sources of electrical transients in tectal neuropil of the frog, Rana pipiens. Brain Res 560:106-121.

Hayes WP, Meyer RL (1988) Normal and regenerating optic fibers in goldfish tectum: HRP-EM evidence for rapid synaptogenesis and optic fiber-fiber affinity. J Comp Neurol 274:516-538.

Hughes T (1990) A light- and electron-microscopic investigation of the opitc tectum of the frog, Rana pipiens. I: The retinal axons. Vis Neurosci 4:499-518.

Jacobson M, Hirsch HV (1973) Development and maintenance of connectivity in the visual system of the frog. I. The effects of eye rotation and visual deprivation. Brain Res 49:47-65.

Katz L, Constantine-Paton M (1988) Relationships between segregated afferents and postsynaptic neurons in the optic tectum of three-eyed frogs. J Neurosci 8:3160-3180.

Katz LC, Shatz CJ (1996) Synaptic activity and the construction of cortical circuits. Science 274:1133-1138.

Keating M, Grant S, Dawes E, Nanchahal K (1986) Visual deprivation and the maturation of the retinotectal projection in Xenopus laevis. $\mathrm{J}$ Embryol Exp Morphol 91:101-115.

Kirkwood PA (1979) On the use and interpretation of cross-correlations measurements in the mammalian central nervous system. J Neurosci Methods 1:107-132.
Kolls BJ, Meyer RL (2000) Increased spontaneous unit activity and appearance of spontaneous negative potentials in the goldfish tectum during refinement of the optic projection. J Neurosci 20:338-350.

Lettvin J, Maturana H, McCulloch W, Pitts W (1959) What the frog's eye tells the frog's brain. Proc Inst Radio Engr 47:1940-1951.

Lyckman AW, Meyer RL (1995) Spontaneous bursting and long-lived local correlation in normal and denervated tectum of goldfish. J Neurobiol 26:109-118.

Maffei L, Galli-Resta L (1990) Correlation in the discharges of neighboring rat retinal ganglion cells during prenatal life. Proc Natl Acad Sci USA 87:2861-2864.

Meek J (1983) Functional anatomy of the tectum mesencephali of the goldfish. An explorative analysis of the functional implications of the laminar structural organization of the tectum. Brain Res 287:247-297.

Meister M, Wong RO, Baylor DA, Shatz CJ (1991) Synchronous bursts of action potentials in ganglion cells of the developing mammalian retina. Science 252:939-943.

Meyer RL (1977) Eye-in-water electrophysiological mapping of goldfish with and without tectal lesions. Exp Neurol 56:23-41.

Meyer RL (1982) Tetrodotoxin blocks the formation of ocular dominance columns in goldfish. Science 218:589-591.

Meyer RL (1983) Tetrodotoxin inhibits the formation of refined retinotopography in goldfish. Brain Res 6:293-298.

Meyer RL, Brink DL (1988) Locally correlated activity in the goldfish tectum in the absence of optic innervation. Brain Res 469:25-36.

Mooney R, Penn AA, Gallego R, Shatz CJ (1996) Thalamic relay of spontaneous retinal activity prior to vision. Neuron 17:863-874.

Murray M, Edwards M (1982) A quantitative study of the reinnervation of the goldfish optic tectum following optic nerve crush. J Comp Neurol 209:363-373.

Murray M, Forman DS (1971) Fine structural changes in goldfish retinal ganglion cells during axonal regeneration. Brain Res 32:287-298.

Murray M, Grafstein B (1969) Changes in the morphology and amino acid incorporation of regenerating goldfish optic neurons. Exp Neurol 23:544-560.

Northmore DP (1987) Neural activity in the regenerating optic nerve of the goldfish. J Physiol (Lond) 391:299-312.

O'Benar JD (1976) Electrophysiology of neural units in goldfish optic tectum. Brain Res Bull 1:529-541.

Oh DJ, Northmore DP (1998) Functional properties of retinal ganglion cells during optic nerve regeneration in the goldfish. Vis Neurosci 15:1145-1155.

Olson MD, Meyer RL (1991) The effect of TTX-activity blockade and total darkness on the formation of retinotopy in the goldfish retinotectal projection. J Comp Neurol 303:412-423.

Penn AA, Riquelme PA, Feller MB, Shatz CJ (1998) Competition in retinogeniculate patterning driven by spontaneous activity. Science 279:2108-2112.

Perkel DH, Gerstein GL, Moore GP (1967a) Neuronal spike trains and stochastic point processes. II. Simultaneous spike trains. Biophys J 7:419-440.

Perkel DH, Gerstein GL, Moore GP (1967b) Neuronal spike trains and stochastic point processes. I. The single spike train. Biophys J 7:391-418.

Potter H (1972) Terminal arborizations of retinotectal axons in the bullfrog. J Comp Neurol 144:269-284.

Purves D (1975) Functional and structural changes in mammalian sympathetic neurones following interruption of their axons. J Physiol (Lond) 252:429-463.

Purves D, Hume R (1981) The relation of postsynaptic geometry to the number of presynaptic axons. J Neurosci 1:441-452.

Rakic P (1977) Prenatal development of the visual system in rhesus monkey. Philos Trans R Soc Lond B Biol Sci 278:245-260.

Schmidt JT, Edwards DL (1983) Activity sharpens the map during the regeneration of the retinotectal projection in goldfish. Brain Res 269:29-39.

Schmidt JT, Eisele LE (1985) Stroboscopic illumination and darkrearing block the sharpening of the regenerated retinotectal map in goldfish. Neuroscience 14:535-546.

Sernagor E, Grzywacz NM (1995) Emergence of complex receptive field properties of ganglion cells in the developing turtle retina. J Neurophysiol 73:1355-1364.

Sernagor E, Grzywacz NM (1996) Influence of spontaneous activity and visual experience on developing retinal receptive fields. Curr Biol 6:1503-1508

Shatz CJ (1996) Emergence of order in visual system development. Proc Natl Acad Sci USA 93:602-608.

Sretavan D, Shatz J (1984) Prenatal development of individual retinogeniculate axons during the period of segregation. Nature 308:845-848.

Stirling R, Dunlop S, Beasley L (1999) Visually evoked extracellular spikes recorded from the lizard optic tectum in vitro are postsynaptic. Soc Neurosci Abstr 25:1939.

Wong RO, Meister M, Shatz CJ (1993) Transient period of correlated bursting activity during development of the mammalian retina. Neuron 11:923-938. 